\title{
ALFONSINOS, SICILIANOS E O MUNDO FEUDAL DO OCIDENTE IBÉRICO. EM BUSCA DA PRIMEIRA GERAÇÃO DE TROVADORES GALEGO-PORTUGUESES
}

\author{
José Carlos Ribeiro Miranda
}

Universidade do Porto

São raros e, de uma forma geral, já vetustos os trabalhos que se propõem desenhar globalmente a compreensão do fenómeno poético galego-português. Durante anos, a conceituação periodológica afinada por Carolina Michaëlis, segundo a qual a primitiva poesia trovadoresca do noroeste peninsular se repartia por vários períodos, entre os quais avultava o chamado "período alfonsino", tido como o mais produtivo e também aquele que qualitativamente se impunha de uma forma mais visível, serviu de referência para os estudiosos de todos os quadrantes ${ }^{1}$. Fundamentado em evidências cronológicas simples —os reinados de dois monarcas, um castelhano e outro, português-, constituiu uma base operativa de uso descomprometido e ágil, conquanto se tornasse evidente que, como sucede com todas as periodologias, qualquer que seja a sua natureza, havia o risco de mascarar realidades bem mais complexas que a investigação, apesar de tudo, ia pondo em evidência. Além disso, em muitos aspectos, foi a luz intensa produzida por esse "período alfonsino" que acabou por fornecer o quadro explicativo não apenas para a fase final do trovadorismo na língua do noroeste peninsular, o que seria óbvio, mas também para a fase inicial, quer a das primeiras tentativas poéticas envolvendo o galego-português, quer a mais mítica época "das origens".

O único intuito sério de superar e aprofundar essa conceituação proveio, a nosso ver, de Giuseppe Tavani que, em sucessivos escritos ${ }^{2}$, foi construindo uma ideia consistente cujo travejamento passava não tanto por uma reformulação das designações periodológicas herdadas, mas antes por uma especificação e extensão desse "período alfosino" como conceito de referência ${ }^{3}$, fa-

1. Cf. Michalis de Vasconcelos (1990: 603 -reprint da edição de Halle, 1904).

2. Referimo-nos às posições teóricas expressas e defendidas por Giuseppe Tavani (1969, 1988). Ver também a síntese de referência A Poesia Lírica Galego-Portuguesa (1990), mais tarde publicada com outro título (Trovadores e Jograis, 2002), mas sem grandes alterações de conteúdo.

3. Embora rebaptizado com a mais actualizada expressão "gerações intermédias" (Cf. Tavani 1990: 254-262). 
zendo agora intervir uma abordagem mais ampla, fundamentada em critérios comparatistas que levavam a situar a produção trovadoresca galego-portuguesa no seu marco europeu, correlacionando-a directamente com a congénere escola poética que havia florescido, também durante o século XIII, em terras sicilianas dominadas pelo imperador Frederico II. Um extenso paralelo entre galego-portugueses e sicilianos foi o que Tavani começou por esboçar até definir cabalmente que esse paralelo se consumava numa extensa afinidade entre as duas escolas poéticas. Tal como a siciliana, também a poesia galego-portuguesa resultaria da iniciativa de um círculo cortesão régio, sendo os seus principais intérpretes idênticos áulicos, aristocratas de corte ou funcionários encarregados de dourar a cultura de um pequeno e isolado, mas poderoso, círculo reinante. Uma poesia de pura imitação dos provençais sem outro alcance que não fosse o de adaptar às circunstâncias específicas da corte em causa entre as quais se contava a escolha de uma nova língua - tanto a ideologia, como a imagética, as técnicas retóricas e os princípios versificatórios daqueles, mesmo que tal sucedesse à custa de um notável empobrecimento e simplificação em qualquer um dos planos considerados.

É certo que a cronologia dos galego-portugueses era mais recuada do que a dos sicilianos, prolongando-se, por outro lado, bem para além destes. Contudo, até na produção, em âmbito siciliano, de discursos extravagantes, como são o textos em que ocorrem vozes femininas, Tavani encontra paralelos flagrantes com o caso galego-português, conquanto admita que o filão dos cantares de amigo ibéricos é de maior imponência, introduzindo um desequilíbrio de monta no processo comparativo.

Deixando de lado as balizas terminais destes dois fenómenos poéticos, em que o galego-português se afirma por uma longevidade que o leva a percorrer ainda grande parte do séc. XIV, enquanto os sicilianos se quedam pelos meados da centúria anterior, o paralelo estabelecido por Tavani seria, mesmo assim, plenamente certeiro e ajustado se a poesia galego-portuguesa tivesse dado entrada no panorama europeu no tempo de Afonso X, apenas com alguns tentames titubeantes anteriores. Mas não foi isso que se passou. Aliás, apercebendo-se de que o seu raciocínio estaria seriamente posto em causa pela evidência da cronologia dos textos e dos autores, Tavani falará não só da mecenática corte de Afonso X, mas também na do pai do rei Sábio, Fernando III, entrando aí, a nosso ver, no primeiro dos pontos onde a comparação entre ibéricos e sicilianos não é sustentável de todo.

Vejamos então. Quando Afonso VIII morre em 1214 e lhe sucede o filho Henrique, que virá a falecer tragicamente três anos depois, a corte castelhana, onde avultara a figura de Leonor, filha de Henrique II e de Leonor de 
Aquitânia, era um dos florescentes centros de apoio à actividade trovadoresca occitânica, tendo sido louvada ou mencionada em tons laudatórios em perto de duas dezenas de textos e confirmadamente visitada por oito trovadores $^{4}$. Ainda em 1218, nos primeiros tempos do reinado de Fernando III, trovadores para lá se deslocam, tentando obter do jovem neto do vencedor das Navas de Tolosa o acolhimento e o favor a que aquela corte os tinha habituado5. Mas os tempos tinham mudado e a atitude do detentor do poder régio castelhano certamente também. Sem pretender avaliar nesta sede as razões profundas que terão ditado tão súbita mudança de comportamento, o que parece certo é que, nos dezoito anos seguintes, não se irá ouvir falar dos provençais por estas paragens, e mesmo quando voltarem a reaparecer referências à corte castelhana em âmbito occitânico, o que virá a suceder no pranto de Sordello por Blacatz, elas serão francamente depreciativas ${ }^{6}$. Somente a partir dessa altura, por volta de 1236, parecem vir a renovar-se quer visitas de trovadores, quer referências positivas à corte castelhana, mas então haverá que ponderar se teriam na verdade como destinatário o Rei Santo ${ }^{7} \ldots$

Por outro lado, em vão procuramos, nessa mesma cronologia, trovadores galego-portugueses na corte de Fernando III, embora estes fossem já numerosos e tivessem uma produção poético-musical regular e consistente. O que sucede é que a actividade dos galego-portugueses se desenrolava predominantemente em geografias bem mais ocidentais dentro da Península, situação que só irá alterar-se exactamente no ano de 1236, quando Pero da Ponte escreve o seu pranto à morte da mulher do rei castelhano, Beatriz da Suábia. Poderá deduzir-se daí existir um mecenato da corte régia castelhana dirigido aos trovadores galego-portugueses? A nosso ver, não. O facto de, nesse mesmo $\mathrm{ano}^{8}$, o trovador galego endereçar igualmente um pranto a Lo-

4. Entre estes, conta-se Ramón Vidal de Besalú que faz dos reis castelhanos personagens centrais do seu Castia Gilós (cf. Alvar 1977: 130-133).

5. É o que sucede com Guilhem Ademar, se for na realidade a Fernando III que o trovador alude nos versos de S'ieu conogues que.m fos enans (cf. Alvar 1977: 166-167).

6. Nas palavras deste trovador, o rei castelhano "non es pros" (apud Alvar 1977: 171). Note-se que também a corte leonesa de Afonso IX será esquecida pelos trovadores provençais de 1218 até à morte deste monarca ocorrida em 1230.

7. Referimo-nos a Peire Bremon de Ricas Novas e a Aimeric de Belenoi, ambos trovadores que terão estado em Castela entre 1237 e 1241 (cf. Riquer 1983: III, 1280 e ss., 1298 e ss.). Cremos que foi também por estas datas que Arnaut Catalán fez a sua tenção bilingue com o futuro Afonso X, a quem trata por "senher", e não após 1252, que todavia tende a ser datação generalizadamente aceite, como se o príncipe D. Afonso não tivesse mantido relações intensas com os meios trovadorescao antes de ser rei... Na realidade, o último documento conhecido referente a Arnaut Catalán é de 1241 (cf. Riquer 1983: III, 1349 e Bec 1984: 154-157). Quanto a Elias Barjols, nem mesmo é certo que tenha estado em Castela.

8. Ou nos finais de 1235 (cf. Panunzio 1967: 46). 
po Dias de Haro e, um pouco mais tarde, um outro a Telo Afonso de Meneses, faz pensar que procedia a uma operação generalizada de solicitação do favor das cortes poderosas de então, nos seio das quais a corte régia castelhana não podia ser, de forma alguma, secundarizada, nada permitindo aferir do acolhimento que teria tido por parte do Rei Santo no exercício da sua actividade. Sabemos que Pero da Ponte prosseguirá na realidade em Castela. Ainda aqui, tudo leva a crer que, à semelhança do que se terá passado com os occitânicos, tal não sucederá ao abrigo do mecenato do rei, mas sim do infante que virá a ser rei somente um punhado de anos mais tarde...

$\mathrm{Na}$ realidade, as observações que fizemos levam directamente a pensar que o Rei Santo se conta entre os monarcas castelhanos dos séculos XII e XIII mais alheios ao fenómeno trovadoresco, o que não só invalida parte das analogias siciliano-ibéricas de Tavani, pois pressupõem a existência de um mecenato régio activo, mas abre a necessidade de reponderar todo o trajecto da poesia galego-portuguesa prévio à corte alfonsina, e de mergulhar seriamente na problemática histórica da génese e evolução deste fenómeno poético cuja memória histórica todo o Ocidente ibérico deve reclamar, propósito a que nos temos dedicado nos últimos vinte anos.

A base de trabalho que constitui actualmente o obrigatório ponto de partida para a concretização de tal objectivo encontra-se no conjunto de dados empíricos, publicados em 1994, fruto da investigação levada a cabo por António Resende de Oliveira (1994). A avaliação destes dados levou, primeiramente, à compreensão do modo como se organiza a distribuição dos autores e a respectiva obra no seio das compilações e outros documentos que os transmitem; e depois, a um melhor conhecimento dos autores e outras personagens da época, bem como do respectivo envolvimento, susceptível de ser constantemente aprofundado à medida que vai sendo publicada informação documental até agora desconhecida. A partir daí, foi possível iniciar uma reponderação sistemática do conteúdo das composições que os nossos trovadores legaram à posteridade, tornando-se também imprescindível o concurso da disciplina filológica, com vista não só a resolver inúmeros problemas de atribuição autoral, mas também a solucionar uma apreciável quantidade de loci critici da fixação textual como condição incontornável de qualquer interpretação séria.

Foi assim que adiantámos, em 1994, o conceito periodológico "segunda geração de trovadores galego-portugueses" (Oliveira / Miranda 1995: 499512). Pretendíamos, antes de mais, dar um novo enquadramento a parte dos trovadores que Tavani considerara genericamente como tendo pertencido à corte de Fernando III es trovadores activos até sensivelmente 1240- já que a partir daí serão mais propriamente "alfonsinos" porque, como dissemos atrás, tanto quanto as informações disponíveis permitem compreender, 
foi a figura do infante, futuro Afonso X, que realmente então os polarizou e apoiou. Como dissemos, é também por essa época, ou mesmo um pouco antes, durante a juventude do futuro Rei Sábio, que começam a afluir de novo a terras castelhanas alguns trovadores provençais.

Era também nossa intenção mostrar que a "segunda geração" constituía um grupo com um perfil social, geográfico e, sobretudo, poético próprio, e que seria um erro confundi-lo com a geração seguinte. Aliás, os limites cronológicos da "segunda geração" 1220- 1240 - eram-nos impostos por várias evidências, das quais destacamos as seguintes: (i) tratava-se de uma época em que os trovadores não haviam dependido de qualquer mecenato régio, mas apenas dos meios senhoriais a que se tinham acolhido; aí residiam tanto a força como as debilidades desta geração; (ii) essas cortes senhoriais situavam-se exclusivamente na Galiza e em Portugal, no que terá sido o único período em que houve uma coincidência substancial entre autores, textos e públicos em torno de uma mesma língua materna e do território onde essa língua era falada; (iii) por último, o perfil social do trovador adquire uma estabilidade muito grande, assentando sobretudo nos membros secundários das linhagens de alguma dimensão, ou nos homens oriundos de pequenas linhagens em situação vassálica.

$\mathrm{Na}$ realidade, os grandes senhores desta região que se dedicaram ao mester poético-musical são poucos e com uma produção manifestamente escassa, embora significativa. Por outro lado, são visíveis os entraves colocados aos jograis para acederem à categoria de compositores ${ }^{9} £$ acto que, todavia, era absolutamente normal em âmbito occitânico ${ }^{10}$. Embora nas gerações seguinte esta situação venha a alterar-se, nem por isso as marcas de um profundo aristocratismo herdado das primeiras gerações deixarão de se fazer sentir, sendo ainda claramente visíveis no modo como virão a organizar-se os cancioneiros, conservando-se os trovadores-cavaleiros separados dos jograis (Cf. Oliveira 1994: 155 e ss.).

Ora a segunda geração de trovadores galego-portugueses, a única cuja actividade se desenrolou verdadeiramente em solo galego e português, encontrou-se condicionada, antes de mais, pelo seu auditório imediato, já que, como dissemos atrás, não é possível identificar, a partir de 1218, qualquer contacto directo entre occitânicos e o Ocidente peninsular. Serão, por isso, as perplexidades e expectativas desse mesmo público a ditar as opções efectuadas sobre a base fornecida pela poesia occitânica, bem assim como a in-

9. Sobre o assunto, ver Oliveira / Miranda (1995: 504-505).

10. Compare-se o perfil social médio do trovador occitânico do séc. XII, por nós esboçado em Miranda (2005: 123-150) com os elementos aduzidos em Oliveira / Miranda (1995) para o meio trovadoresco galego-português. O contraste não poderia ser mais flagrante... 
trodução de uma quantidade apreciável de temas, motivos e escolhas formais desconhecidos dessa poesia de referência.

No plano temático-ideológico, salientaremos, por exemplo, a sobrevalorização da problemática da mulher guardada, que atravessa transversalmente todos os géneros, vindo a desembocar na questão do rapto da mulher, tão típica do ambiente galego-português desta fase ${ }^{11}$. Por outro lado, impõe-se a suprema inovação que é o cantar de amor de locutor feminino, com os tempos designado "cantar de amigo", vindo depois, já perto do séc. XIV, a generalizar-se como "cantiga de amigo" 12 . No plano formal, é de chamar à atenção para o verso longo e cesurado, particularmente vistoso e anacrónico quando associado ao dístico com refrão, modelo versificatório que ganha imponente presença mas também quase se esgota nos trovadores e jograis desta geração ${ }^{13}$.

Além disso, as reorientações da linguagem poética herdada dos occitânicos foram extensas e profundas, com um inevitável processo de selecção dentro do manancial expressivo que essa linguagem oferecia, a par de sérias inovações, somente explicáveis não por um qualquer empobrecimento na sequência de uma imitação passiva e mecânica, mas, em muitos casos, por um processo amplamente produtivo que falta provavelmente compreender em todo o seu sentido e extensão.

Ora, os trovadores e jograis alfonsinos são antes de mais herdeiros desta tradição galego-portuguesa já instituída @- trobar coma Bernal de Bonaval, de que falava Afonso X, na célebre composição contra Pero da Ponte ${ }^{14}$ conquanto se observe que muito fizeram por reconduzi-la à matriz provençal, obecedendo, uma vez mais, aos desígnios traçados pelo Sábio rei. Mas isso é já assunto que nos desviaria do nosso propósito. O tema para que pretendemos seguidamente chamar a atenção é o que se situa num ponto cronologicamente anterior: se entre 1220 e 1240 havia florescido uma segunda geração trovadoresca galego-portuguesa, era óbvio que estávamos a considerar que essa não fora a primeira, e uma outra geração a tinha precedido.

11. Cf. Oliveira (2001: 35-50). Pelo que nos diz respeito, dedicámos ao tema um conjunto de artigos publicados na revista O Tripeiro e posteriormente reunidos em Miranda (1996).

12. Questão central nos estudos galego-portugueses, o cantar de amigo foi objecto de recentes abordagens de síntese entre as quais destacamos Brea / Lorenzo Gradín (1998). Para os nossos pontos de vista, remetemos o leitor para Miranda (1994) enquanto não cumprimos a promessa de dar à estampa uma abordagem mais substancial do assunto.

13. A aparentemente inesperada associação entre o verso longo e cesurado e os primeiros cantares de amigo, que tanto desconforto provocou a certos editores, aguarda ainda quem the dedique alguma atenção mais do que fugaz. Entretanto, veja-se, sobre o assunto, Lapa (1982: 63-96) e Ferreira (2001: 293-309).

14. "Pero da Ponte, pare-vos en mal" (B 487/V 70), vv. 13-14. 
E assim entrávamos num dos mais nebulosos e controversos temas dos estudos galego- portugueses...

À partida, antes mesmo de avançar na ponderação e interpretação dos dados empíricos que a investigação proporcionava, impunha-se desfazer os mitos e as fantasias que insistentemente haviam povoado os manuais sobre o assunto, na esteira aliás dos trabalhos dos primeiros investigadores sobre a matéria. Sem pretensão de exaustividade, baste por agora mencionar a célebre polémica em torno da "Cantiga da Guarvaia", atribuída a um irmão do prócere português Pero Soares, o Escaldado, da linhagem dos Velhos, e membro activo da corte do rei português D. Sancho I (1185-1211) ${ }^{15}$. Nessa linha de raciocínio, a filha de D. Paio Moniz aí mencionada seria D. Maria Paes Ribeiro, a conhecida amante do monarca português, do qual teve seis filhos. Por sua vez, o rei D. Sancho teria sido o autor do "Ai eu coitada..." (B 456), cantar de amigo onde ressoaria a voz da romântica amada do rei, o qual passaria, assim, a ostentar uma vetusta cronologia, que o remeteria para os primeiros anos do séc. XIII ou mesmo para o final da centúria anterior ${ }^{16} \ldots$ Refira-se que já a "Cantiga da Guarvaia" era datada por Carolina Michaẻ is de $1189^{17} \ldots$

Felizmente, embora a investigação histórica tenha marcado passo ao longo de grande parte do séc. xx, hoje em dia já ninguém minimamente informado acerca destas matérias deverá duvidar da atribuição da "Guarvaia" a um pequeno cavaleiro galego dos anos 1230 a 1240, ou ignorar que D. Sancho I não é autor do Ai eu coitada..., e ainda que a figura da Ribeirinha não esteve intrometida nas cogitações trovadorescas (apenas nas linhagísticas, onde é, de facto, raptada ${ }^{18}$...). Impõe-se reconhecer que não existiu qualquer interesse de uma corte régia em Portugal pela poesia trovadoresca antes de meados do séc. XIII e ainda que, por muito que pese a um certo espírito patriótico português, pura e simplesmente não é possível identificar sinais de

15. Resumo do problema e respectiva bibliografia em Ramos (1989: 1097-1111). Ver ainda Vallín (1996). Em Miranda (2004b: 443-458) aduzimos razões que levam a pensar ser anónimo o conjunto de cantares em que se inclui a "Guarvaia".

16. Cremos que a atribuição desse texto a Afonso X está consagrada desde Pellegrini (s/d: 23-53), nada tendo surgido, na investigação levada a cabo nos últimos anos, que levante dúvidas credíveis sobre essa atribuição.

17. A identificação da "filha de D. Paai Moniz", referida nessa composição, com D. Maria Pais Ribeiro remonta aos escritos do polígrafo António Ribeiro dos Santos concluídos antes de 1810, recentemente editados por Arbor / Pulsoni (2004: 721-789).

18....se é que o rapto alguma vez teve lugar. Pelo menos algumas das informações incluídas nessa narrativa são claramente fantasistas, nomeadamente a punição do raptor pelo rei de Leão. Sobre o assunto, ver Barradas (1998: 146-163). 
poesia trovadoresca no reino de Portugal antes de Garcia Mendes de Eixo retornar definitivamente do exílio leonês ${ }^{19}$ (e galego) pelos inícios de $1218^{20}$.

Rigorosamente, o mesmo é possível dizer relativamente a uma lírica autóctone, não dependente da poesia provençal, que se teria revelado nos cantares de amigo, vindo a ter a fortuna que se conhece ao longo do séc. XIII. Só com recurso a uma crença muito profunda é possível situá-la antes das tentativas vigorosas de Fernan Rodrigues de Calheiros, de Vasco Praga de Sandim e de Bernal de Bonaval ${ }^{21}$, aqueles que oferecem seguras credenciais de antiguidade; o que não significa, de maneira alguma, que os ingredientes métricos, lexicais, e até imagéticos que se acham no género cantar de amigo não possuam, cada um por si, uma história ancestral própria.

Mas é de trovadores, de mecenatos, de meios receptivos e de instrumentos de perduração de todo esse material que falamos de momento, não das técnicas e dos conteúdos poéticos manobrados por trovadores e jograis ao longo de cerca de 150 anos, nem do talento inventivo neles investido. Assim, arredada a poeira das fantasias, voluntarismos, conjecturas e credos vários, o que permanece ${ }^{22}$ ?

Antes de mais, o naipe de trovadores que encabeça o Cancioneiro da Biblioteca Nacional, fundamentalmente complementado pela lista de nomes conhecida como Távola Colocciana, elaborada pelo próprio Angelo Colocci à vista do Cancioneiro da Biblioteca Nacional ainda íntegro, ou seja, quando este volumoso códice continha todos os textos dos dez primeiros autores, dos quais se perderam entretanto mais de dois terços.

A Tavola é preciosíssima para reconstruir os grupos e, a partir deles, emitir hipóteses controladas sobre as cronologias e as geografias percorridas nas etapas fundacionais da poesia trovadoresca em galego-português. Embora escassos, os textos são absolutamente valiosos, tanto de um ponto de vista documental como poético, tendo em atenção a história literária ou até a dimensão linguística, pese embora tratar-se de textos transmitidos por teste-

19. Ver dados históricos aduzidos na recente biografia de Afonso II (Vilar 2005).

20. O único trovador occitânico de que temos notícia de ter estado em Portugal é Afonso II, rei de Aragão, quando visita Coimbra nos finais de 1195. Mas cremos que o terá feito na qualidade de rei doente e penitente, em busca de apaziguamento das graves querelas que atravessavam a monarquias ibéricas, e longe de qualquer preocupação literária e musical. Virá a morrer, aliás, logo após essa viagem. A primeira notícia da presença de alguém ligado à actividade trovadoresca galego-portuguesa em Portugal é fornecida pelo documento onde D. Gonçalo de Sousa tem, como confirmante de uma doação feita em Lisboa, aonde se teria deslocado em 1221, um "Abril jogral", há anos identificado por A. Resende de Oliveira como o Abril Peres que elabora uma tenção com Bernal de Bonaval.

21. Cf. Miranda (1994).

22. Na exposição que fazemos deste ponto em diante, remetemos o leitor para o nosso livro Miranda (2004a). 
munhos muito tardios, nuns casos, excêntricos em alguns outros, cujo acesso está dependente das sempre controversas práticas da crítica textual, disciplina fora da qual, infelizmente, não se vislumbra outra abordagem que não seja o silêncio.

Estamos num dos raros casos em que a tradição manuscrita conhecida da poesia galego-portuguesa pode ser enriquecida pela tradição manuscrita occitânica, já que dois dos textos desta fase se encontram aí preservados, avolumando o caudal de dificuldades que a respectiva fixação crítica acarreta referimo-nos às coblas galego-portuguesas inseridas, respectivamente, por Raimbaut de Vaqueiras e Ramón Vidal de Besalú, em poemas de sua autoria.

Como dissemos atrás, aquilo que permitiu sair das explicações parciais e contraditórias até agora predominantes sobre a primitiva actividade dos trovadores galego-portugueses ${ }^{23}$, avançando para uma hipótese global e consistente, embora, como deve suceder com qualquer processo de conhecimento, sempre provisória e sujeita ao sistemático crivo da contradição, foi o aumento do caudal de informação histórica que entretanto se veio a tornar disponível, desde os cartulários monásticos, aos documentos das chancelarias régias até à republicação dos Livros de Linhagens e respectivos índices.

A identificação de mais personagens desta fase inicial, ou o melhor conhecimento do respectivo trajecto, veio possibilitar que certos vultos insuspeitados emergissem, enquanto outros, sobre os quais havia fortes expectativas, se ficassem pelo apagamento e pelas franjas do fenómeno trovadoresco. E aqui, para além de João Soares de Paiva, cujo papel é incontornável por razões que exporemos adiante, afirma-se a figura tutelar de Rui Diaz de los Cameros e, numa fase já mais adiantada, a acção levada a cabo pelo Sousão Garcia Mendes d'Eixo tendo esta, todavia, já mais cabimento numa exposição sobre a segunda geração do que sobre a primeira.

23. Não seria de esperar que, há cerca de um século, as hipóteses explicativas para o surgimento de um fenómeno complexo, como é o trovadorismo galego-português, fossem mais do que um avassalador elenco de informações, indícios e interpretações contraditórias, ainda não sujeitas à dura prova do tempo. A recente publicação da tradução portuguesa das Randglossen, de Carolina Michalis de Vasconcellos (2004), apenas vem confirmar esse facto. Veja-se, por exemplo, que D. Carolina, na Glosa XI, começa por situar João Soares de Paiva junto a Tudela (p. 299) para terminar dizendo que se havia "mudado para Barcelona" para aí aprender a "arte provençal" (p. 312), vencendo muitas centenas de quilómetros com surpreendente facilidade. Ou ainda a convicção de que o Paiva teria sido grande feudatário do rei de Aragão, e que o seu feudo se situaria em Pavia, perto de Cervera (versão adiantada em Cancioneiro da Ajuda, Michaß̉ is de Vasconcelos 1990, II: 565) quando, ao mesmo tempo, reconhece que Paiva é nome de linhagem português, e se torna claro que há total incompatibilidade entre essa Pavia de Aragão e a colocação junto à fronteira "entre Navarra e Aragão" que atribui ao trovador (p. 299). Que algumas destas ideias, como a do feudo aragonês, cuja existência procurámos confirmar durante anos sem qualquer êxito, permaneçam ainda hoje como certeza em obras de grande responsabilidade, é algo que só pode provocar desalentada surpresa (cf. Tavani 2002: 408). 
Comecemos, então, pelos compositores e respectivos textos, para depois ajuizarmos como se agrupam, que trajecto percorreram e em que cronologias o fizeram.

$\begin{array}{lll}\text { Airas Moniz d'Asme } & 2 & {[2]} \\ \text { Diego Moniz } & 6 & {[2]} \\ \text { Pero Pais Bazoco } & 7 & \\ \text { João Velaz [de Guevara] } & 2 & \\ \text { Don Juano } & 1 & \\ \text { Joan Soares de Paiva, } & 7 & {[1]} \\ \text { Pero Rodrigues da Palmeira } & 2 & \\ \text { Rodrigo Diaz dos Cameiros } & 3 & \\ \text { Airas Soares } & 3 & \\ \text { Osoir'Anes [Marinho] } & 7 & {[7]}\end{array}$

Embora se tenham, ao longo dos tempos, levantado dúvidas sobre se o critério cronológico de ordenação dos autores nos apógrafos italianos se verificava consistentemente, cremos que, no tocante às primeiras gerações, ele está de facto presente, conquanto não seja possível falar nunca de uma obediência sistemática a esse critério.

Um dos nomes que mais perplexidade têm causado é exactamente o do iniciador, Airas Moniz d'Asme, que Vicente Beltrán recentemente (1985: 45-57) pretendeu adiantar para a corte alfonsina, sem êxito, na nossa opinião. Mas permanece a pergunta: porque terá aquele trovador sido escolhido para encabeçar a compilação? Será o mais antigo? Para solucionar esta questão será necessário cruzar vários tipos de dados, já que os fornecidos por um único ponto de vista serão sempre insuficientes. Por exemplo, tem passado quase despercebido que uma das suas composições é um diálogo entre um homem e uma mulher socialmente identificados, modalidade da qual somente se encontram dois exemplares na poesia occitânica ${ }^{24}$. Dentre esses dois, o que se apresenta mais próximo do nosso trovador é o texto da autoria de Raimbaut de Vaqueiras, nome conhecido quando se fala em occitânicos e galego-portugueses, já que foi autor de uma das atrás mencionadas coblas em galego-português.

Se juntarmos a isto o facto de o trovador Perdigon referir, na tornada de uma das suas canções, um En'Arias, nome totalmente desconhecido em âmbito occitânico, que já estudiosos como Istvan Frank (1949: 199-226) viram como muito provável que fosse o nosso trovador; e se tivermos ainda em conta que tanto Perdigon como Vaqueiras integraram a corte de Bonifácio de Monferrato num período anterior a 1203, não será difícil aceitar a franca possibilidade de Airas Moniz, no séquito de alguém necessariamente pode- 
roso, ter visitado aquela corte italiana de grande projecção trovadoresca, confirmando-se assim a sua antiguidade como trovador.

Todavia, como tentámos mostrar em sede própria, os textos conhecidos deste trovador galego parecem dirigir-se a um público especificamente situado no Ocidente peninsular, não apenas pela língua de que fazem uso, mas também pela forma e tonalidade assumida pelos respectivos enunciados poéticos ${ }^{25}$. Veremos mais adiante como será ainda possível adiantar mais dados, extraídos da sede literária, que permitirão delimitar melhor este trajecto e apontar para uma cronologia bastante recuada.

É nossa convicção que a primeira compilação trovadoresca p- rovavelmente aquilo que António Resende de Oliveira (1994: 179 e ss.) identificou como "Primeiro Cancioneiro de Cavaleiros"- colocou Airas Moniz à cabeça porque, no meio onde se efectuou essa compilação, era reconhecida a este trovador a autoridade de um fundador. Mas tal situação iria alterar-se com a inserção, mais adiante, de material decerto proveniente de rolos que continham toda a produção de um grupo onde pontificavam os nomes de João Soares de Paiva e, em especial, de Rui Dias de los Cameros, o poderoso magnate castelhano que virá a dirigir uma das alas cristãs na batalha das Navas de Tolosa. Trata-se do conjunto identificado atrás em itálico.

Um grupo coeso? Cremos que sim e, mais ainda, que foi aquele que verdadeiramente deu início às experimentações trovadorescas em galego-português. Vejamos então o que foi possível apurar, começando pelo Cameros. Em termos de importância social e política, não há ali quem se lhe compare, embora o Joan Velaz de Guevara tenha também chegado a ocupar funções políticas importantes a ocidente da região riojana. Os portugueses Paiva e Palmeira, qualquer que tenha sido o respectivo trajecto ao longo de dezenas de anos, não deixaram sinais de terem alguma vez ocupado o topo das pirâmides do poder no mundo feudal de então. Nessa ordem de raciocínio, se tivermos em atenção o modo como funcionavam os grupos senhoriais neste particular contexto, Rui Diaz será sempre a figura a ter em conta como personalidade aglutinadora desse conjunto de trovadores, até porque também era já, confirmando o prestígio da linhagem a que pertencia, o mais activo mecenas de trovadores occitânicos que encontramos em ambiente do centro e ocidente da Península, exceptuando as cortes régias de Leão e Castela, ultrapassando neste aspecto Haros e Laras.

Rui Diaz é politicamente um homem da esfera territorial castelhana, embora a sua linhagem seja de origem navarra. Por isso, é particularmente relevante que, após a morte do pai, Diego Jimenez, ocorrida em 1187, Rui Diaz

25. Ver a nossa interpretação do motivo "honrar a barba", presente numa das composições deste autor, em Miranda (2004a: 135 e ss.). 
venha a confirmar documentação régia castelhana apenas duas vezes, para logo desaparecer, inaugurando uma ausência de treze longos anos. Ora, é durante o período correspondente a essa ausência que os dados conhecidos permitem situar as primeiras manifestações do mester poético-musical galego-português, adensando a perplexidade em torno das circunstâncias que levaram a que tal se tivesse tornado possível.

A linhagem dos Cameros encontra-se também muito ligada a Leão e, por via da mãe de Rui Diaz, Guiomar de Trastâmara, especificamente à Galiza, o que, entre outros aspectos, explica o domínio do galego por parte deste trovador. Já o pai, Diego Jimenez, conhecera um período de expatriação em Leão, entre 1178 e 1180, durante o qual fora feito tenente da própria cidade sede do reino. Mas não é aí que vamos encontrar Rui Diaz durante a sua prolongada ausência da corte régia castelhana.

$\mathrm{Na}$ realidade, tendo os Cameros detido a tenência da importante praça de Calahorra da mão dos reis de Navarra, entre 1185 e 1197, segundo é indicado pela documentação navarra consultada por Agustin Ubieto Arteta (1973), não é difícil perceber que os Cameros, pelo menos entre finais de 1187 e a morte de Sancho VI, ocorrida nos finais de 1194 , tomaram o partido dos navarros no conflito que então se vivia na região, partido que virão a abandonar aos poucos, sobretudo com a subida ao trono do novo rei Sancho VII. Assim, terá sido no norte da Rioja, na terra dos Cameros, que este grupo senhorial permaneceu durante o período em questão ${ }^{26}$, sendo o texto de João Soares de Paiva um documento impressionante da derradeira fase do trajecto político por esse grupo percorrido no contexto navarro-castelhano-aragonês, testemunhando a ruptura política com a Navarra. Relembremos que, no seu magnífico Ora faz ost'o senhor de Navarra, o trovador português leva a cabo, em termos tão empolados quanto era usual em Bertrán de Born, que toma como modelo, uma diatribe demolidora contra as capacidades bélicas de Sancho VII de Navarra.

Ora, o lapso de tempo em que cremos que os Cameros terão estado em íntima aliança com os navarros, 1187-1195, é também um período crucial na cena trovadoresca, já que coincide com o cativeiro de Ricardo Coração de Leão, o senhor a quem Bertrán de Born se menteve fiel na parte final da sua existência, e com o casamento daquele filho de Leonor de Aquitânia com a filha do rei navarro. Aliás, Bertran de Born, com quem Joan Soares de Paiva aprendeu a técnica da invectiva guerreira, era um firme defensor dos navarros, sobretudo contra os rivais aragoneses.

26. Atendendo aos contactos, que os textos deixam entender, deste grupo tanto com a corte dos marqueses de Monferrato como com o poderoso séquito senhorial de Ricardo Coração de Leão, na vassalidade do qual se situava Bertran de Born, não é de excluir a possibilidade de o Cameros e seus pares terem estado fora da Península na altura em que decorriam as operações da Terceira Cruzada. Caberá à investigação futura apurar a viabilidade desta hipótese. 
Este período, e este contexto político, devem ter sido cruciais para a assimilação do canto trovadoresco occitânico por parte de um grupo onde virá a pontificar o Paiva, o Palmeira e os restantes nomes que acima indicámos. Entre os quinze textos que deixaram para a posteridade, não sabemos quantos nem quais serão o resultado das primeiras tentativas poético-musicais, porque quase todos se perderam. Avaliando a composição do grupo, porém, não é difícil compreender as razões identitárias que terão conduzido à procura de uma alternativa ao occitânico, tendo essa escolha recaído essencialmente no galego-português. Por outro lado, parece fora de dúvida que a ruptura com a Navarra, em curso a partir de 1195, representando a anulação da principal via de comunicação com o mundo de Além-Pirenéus, só poderá ter reforçado ainda mais a opção pelo galego-português como língua de prestígio, da poesia e do canto.

Aproximando-se o final do séc. XII, não tardará que Rui Diaz preste de novo homenagem a Afonso VIII, alinhando com o poder político dominante na região onde a linhagem dos Cameros se encontrava enraizada. Mas, por outro lado, foi também nessa altura que o senhor dos Cameros decidiu renovar relações profundas com o reino de Leão, e com a Galiza em particular, onde virá a passar o ano de 1201 assumindo cargos curiais ao nível da sua importância no contexto ibérico. Sinuosidades e duplicidades da política dos grandes grupos senhoriais que não constituem surpresa no conturbado período da passagem do séc. XII para o século seguinte.

Se, com a reorientação política da linhagem que o protegia a fastandose da Navarra e direccionando a sua política para o interior da Penínsulao galego-português vira reforçada a legitimidade e o sentido do seu uso, agora, rumo a Ocidente, a Leão e à Galiza matricial, ganhava sem sombra de dúvida um novo impulso e a possibilidade de contar com um renovado auditório. Mas infelizmente a sequência dos acontecimentos não viria a ser tão eufórica quanto à primeira vista seria de prever...

Antes de avançar a caminho de Leão e da Galiza, gostaríamos de fazer notar que nos parece francamente provável que o núcleo inicial, que designámos como Paiva-Cameros, tenha assumido alguma projecção bem para fora dos limites da Península Ibérica. Pela cronologia em que se situa a ntes de 1203, - o descort plurilingue de Raimbaut de Vaqueiras só pode ter ido buscar a sugestão para a cobla escrita em galego-português à produção conhecida daquele grupo castelhano-leonês-galego-português ${ }^{27}$. 


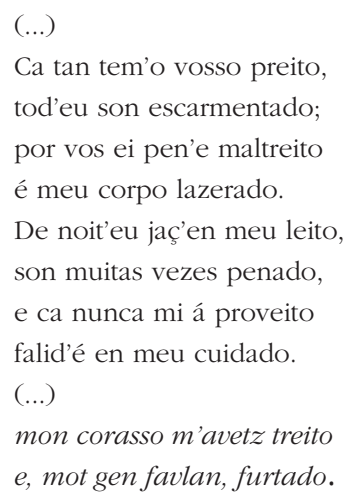

Também a cobla em galego-português citada por Ramon Vidal de Besalú, e atribuída por este poeta a um castelhano do qual não sabe dizer o no$\mathrm{me}^{28}$, deverá certamente remontar à produção poética deste grupo.

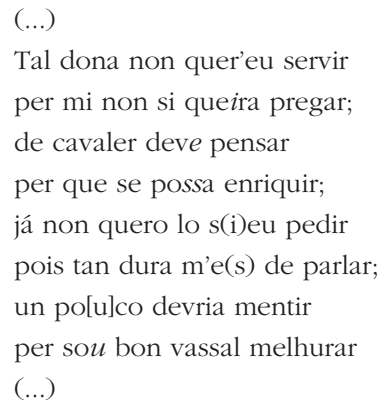

Tal apropriação poderá ter-se dado entre os finais do séc. XII e os inícios do séc. XIII, uma vez mais na corte italiana de Bonifácio de Monferrato que Besalú também frequentou, ou então na corte castelhana antes de 1210, o que obrigaria a pensar que o Cameros, na sequência da sua aproximação política ao reino do centro da Península, terá levado para essa corte a poesia em galego-português numa fase em que, manifestamente, não havia ainda condições para ser aí assimilada e protegida.

Em todo o caso, com as coblas de Vaqueiras e Besalú estamos perante duas manifestações indirectas de uma produção poética de amor galego-portuguesa que, para além delas, se encontra totalmente perdida.

28. Em Miranda (2004a: 179-202) não só procurámos levar a cabo uma revisão crítica do texto, como tantámos fundamentar a identificação do autor, a datação e a geografia em que a sua produção se terá situado. 
De retorno à coroa leonesa e às terras galegas, quando esperaríamos assistir ao surgimento de uma nova e impetuosa fornada de poetas-cantores, ávidos de fazer frutificar a nova palavra e o novo canto, eis que deparamos com um modesto grupo de trovadores nos primeiros anos do séc. XIII, acantonado sobretudo na década de 1210, tanto quanto as escassas indicações existentes permitem entender. E se são correctos os dados biográficos apurados por António Resende de Oliveira, nesse grupo ocidental da primeira geração, que prolonga as experimentações do grupo Paiva-Cameros, são maioritários homens da região de Ourense, o que aumenta ainda mais a nossa perplexidade. Observe-se, então, no seguinte mapa o que poderá ter sido o trajecto da primeira geração ${ }^{29}$ :

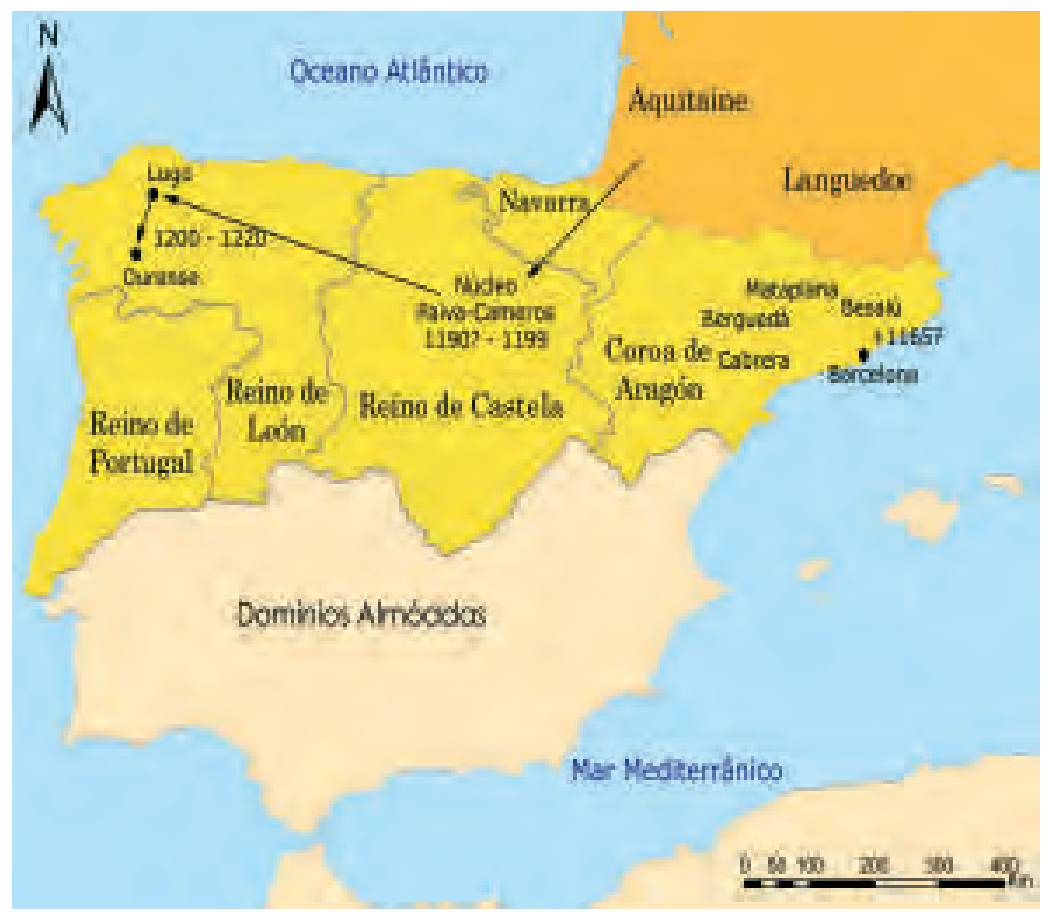

29. Agradecemos à geografa Andreia Pereira a ajuda prestada na realização deste mapa. 
É surpreendente o facto de não ser possível detectar nenhum grupo senhorial que assegure o mecenato e o apoio que, no caso dos occitânicos, se tornava indispensável à actividade trovadoresca. Talvez essa falha seja a explicação para que de cerca de quinze cantares em menos de dez anos, no caso do núcleo Paiva-Cameros, se passe apenas a cerca de vinte e cinco no dobro do tempo, já incluindo neste côn puto o vetusto e algo isolado Airas Moniz d'Asme.

Escassa progressão, portanto, reveladora de uma aclimatação difícil do canto trovadoresco em terras galegas. Será necessário esperar pela figura de Garcia Mendes d'Eixo, autor de um insólito mas eufórico cantar no louvor das terras e dos homens, para identificarmos quem virá a polarizar um grupo de galegos do Sul e de portugueses do Norte que darão ao fenómeno uma dimensão tal que o enraizará definitivamente. O facto de o nome de "Roy de Spanha", certamente Rui Diaz dos Cameros, aparecer como aquele a quem o texto de Garcia Mendes é dedicado (?) ${ }^{30}$ pode indicar que o mecenato trovadoresco em Leão-Galiza continuou a ser assegurado por esta linhagem castelhana desde 1200 até à altura em que os Sousões fazem a sua aparição na cena trovadoresca. Mas nesse momento, como deixámos dito, estará já a "segunda geração" à vista.

Por último, a questão da língua, afinal aquela que constitui a principal preocupação dos especialistas aqui reunidos e sobre a qual não poderemos deixar alguns apontamentos decorrentes do trabalho realizado. Temos utilizado indistintamente o termo "galego-português" não apenas para caracterizar a língua utilizada por estes trovadores por oposição ao occitânico, mas também para definir os homens que o integram, o que facilmente se verifica não ser inteiramente exacto nem num caso nem no outro.

É claro que há momentos em que certos aspectos da língua, neste caso da língua na sua execução poética, podem dar um contributo definitivo às delimitações cronológicas e ajudar a compreender com se organizavam os grupos e que contacto tinham entre si. É o que se passa no tocante à utilização, em quase todos os autores mencionados com cantares de amor, do verbo pensar regido da preposição de, com o significado de "curar" ou "alimentar", mas entendido numa acepção metáfórica de sentido veladamente erótico, já que se trata de pedir à dona que conceda esse alívio a quem a solicita e a serve.

Osoir'Anes Marinho, Diego Moniz, Airaz Monis d'Asme, trovadores cuja obra sobreviveu, pelo menos em parte, mas também o desconhecido caste-

30. Veja-se a epígrafe que acompanha o texto no Cancioneiro da Biblioteca Nacional, fol. 99 r, em Miranda (2004c: 41-48). 
lhano citado por Besalú, se a nossa leitura desse texto se revelar aceitável, fazem uso dessa metáfora que irá rapidamente ser abandonada por todos os trovadores da segunda geração e das seguintes, para apenas aflorar nos estranhos versos de Pero Meogo (B 1186/ V 791), exactamente num contexto altamente erótico. Trata-se de uma marca geracional fortíssima que confirma, segundo cremos, estarmos na realidade perante a "primeira geração de trovadores galego-portugueses".

Mas o facto de comungarem de um traço de linguagem poética que os identifica não quer dizer que a língua por eles utilizada fosse consistentemente o galego-português, pelo menos nos moldes que vieram a tornar-se canónicos nos trovadores posteriores ao longo de cerca de cento e cinquenta anos de uma actividade literária ininterrupta. É particularmente importante, deste ponto de vista, que possam ser convocados dois textos provenientes de uma tradição manuscrita diferente da galego-portuguesa, visto que sobre esta recairá sempre a suspeita de ter procedido a um conjunto de regularizações que transfiguraram aquilo que seria a língua escrita sobretudo das fases mais temporãs do fenómeno trovadoresco do Centro e Ocidente peninsular.

Conquanto de fixação difícil e incerta, dependente da resolução de uma enorme quantidade de incompreensões de redactores que não dominavam a língua dos textos que copiavam, tanto a tradição manuscrita do poema de Vaqueiras como a do breve poema inserido por Besalú no seu So fo le tems c'om era jais contêm um punhado de ocorrências que devem levar a meditar sobre a natureza da língua praticada pelos homens que integravam o grupo Paiva-Cameros. Pela constituição do grupo, pela origem da maioria dos seus membros, pelas solidariedades familiares e, possivelmente, vassálicas em que se encontravam envolvidos, e ainda pelas características do único texto desse grupo directamente sobrevivente $\Theta$ - Ora faz ost'o senhor de Navarra - o galego-português era realmente a língua dominante, embora ostentasse características particulares cuja origem se situará nas condições concretas em que foi promovido a língua de canto e de escrita.

Entre estas avulta a interferência do modelo provençal, visível não apenas nos vários planos de estruturação da língua, mas também nas opções grafemáticas, diferentes, em certos aspectos, das que em época próxima viriam a praticar-se quer na escrita notarial do galego-português ${ }^{31}$, quer na es-

31. Sabendo que uma parte dos documentos mais antigos nos quais foram identificados os primeiras breves enunciados em galego-português se referem a familiares de Joan Soares de Paiva, será tentador relacionar ambos os factos e assumir que o galego-português escrito (notarial e trovadoresco) teria uma mesma origem e... portuguesa. Tal é explicitamente defendido por Martins (2001a: 23-71). Cremos ter mostrado, todavia, que tanto a geografia em que ocorrem 
crita que virá a emanar da corte de Afonso II de Portugal ${ }^{32}$. A grande mobilidade deste grupo senhorial, bem assim como a integração no seu seio de gente proveniente de várias zonas linguísticas, poderão ainda justificar certas ocorrências tanto lexicais como morfológicas desconhecidas do galego-português, mas devedoras de outros falares próximos, nos quais sobressai o antigo leonês e até o castelhano ${ }^{33}$. Interrogamo-nos sobre se as dificuldades sentidas pelos editores do descort plurilingue de Vaqueiras não serão devidas a que a vasta tradição manuscrita dessa obra seja, apesar de tudo, consistente em transmitir, nos versos "galego-portugueses", leonesismos, castelhanismos ou outras interferências linguísticas que fariam inevitavelmente parte do texto na sua origem ${ }^{34}$. Outro tanto poderá passar-se com a cobla do castelhano desconhecido ${ }^{35}$.

Já em 1995 deixámos expressa a ideia de que esse núcleo inicial da poesia trovadoresca em vulgar peninsular, conquanto maioritariamente galego-

ambas as produções escritas, como as característias oferecidas por cada uma delas, devem levar a descartar tal possibilidade. Nesse sentido se pronunciou igualmente Souto Cabo (2003a: 329385). Como afirmámos antes, o galego-português escrito emana de três pontos autónomos a escrita notarial de Entre-Douro e Minho, a cúria régia de D. Afonso II e o primeiro núcleo trovadoresco- - gerando tradições diversas, tendo sido necessárias várias gerações para que essas tradições se viessem a reunir num só caudal. Reconhecidamente, tal só sucederá, na melhor das hipóteses, na parte final do reinado de D. Afonso III.

32. Reafirmamos aqui a ideia de que o esforço de escrita em vulgar do reinado de D. Afonso II, conhecido essencialmente pelas várias cópias que terão existido do testamento de 1214, pode ter sido ainda mais extenso, já que são legítimas as dúvidas sobre a língua em que primitivamente terão sido redigidas as leis de 1211-1212 (não de 1217 como por lapso adiantámos em Miranda 2004: 197, nota 354), dúvida que foi já levantada por Mattoso (1993: 113), sendo por isso assunto em aberto e carecendo de estudo aprofundado. Por outro lado, é de crer que Afonso II prolongasse e adaptasse uma tradição de escrita em vulgar que vinha já de Leão e Castela. O Tratado de Cabreros, redigido em 1206, constituiria certamente um bom modelo a seguir, no tocante à escrita solene em vulgar, mas não podemos deixar de ter também presente um texto como o Foro de Villafranca, cuja versão em vulgar pode ter sido redigida numa época bastante recuada, tendo em atenção os abundantes arcaísmos que possui. Conquanto pareça não existirem dúvidas sobre a sua primitiva redacção em latim, não encontrámos ainda esclarecimento suficiente para as interrogações que este belo texto levanta.

33. Encontramos aqui motivos acrescidos para confirmar as palavras de Boullón Agrelo (2005: 57) quando afirma: "a difusividade ou borrosidade non se dá só entre o latín e o romance senón tamén entre as variedades que logo se irían conformando como linguas diferenciadas..." .

34. Referimo-nos a certas formas reveladoras desta indefinição linguística que se encontram especialmente na tornada, tais como "corasso", "avetz" e "favlan", que nem a mais voluntarista prática de crítica textual consegue elidir. E será oportuno lembrar que fenómenos de interferência linguística múltipla no registo escrito do Noroeste peninsular se revelam mesmo em documentos totalmente alheios à liberalidade da escrita literária, como sucede nos Fueros de Avilés e de Oviedo (cf. Lapesa 1948).

35. Na cobla do "castelhano desconhecido" citada por Ramón Vidal de Besalú, a tradição manuscrita não autoriza, a não ser por conjectura, que se alterem as formas "poco", "sieu" e "es" (pr. ind. v. seer, $2^{a}$ p. sing.). 
português, poderia ter constituído como que uma Babel original ${ }^{36}$. A especialização definitiva em torno do galego-português só teria ocorrido numa segunda fase, na sequência do trajecto do grupo, com uma ancoragem definitiva em terras galegas. Mesmo assim, Garcia Mendes d'Eixo, já numa fase adiantada da segunda década do séc. XIII, ainda se terá sentido suficientemente à-vontade para redigir um texto inusual, plurilinguístico, em que de algum modo evocava essa prática que certamente ainda conhecera.

Terminemos: desde que remetida aos seus limites precisos, a analogia entre os "alfonsinos" galego-portugueses e os "sicilianos" da corte de Federico II pode ser de algum modo viável como forma de compreender a natureza do fenómeno trovadoresco na franjas de irradiação da poesia occitânica num período já tardio. Mas é necessário ter em conta que, no ocidente da Península Ibérica, há uma outra realidade prévia, de sentido fortemente diverso, que se manifesta na aceitação e apropriação dos modelos trovadorescos e sua transformação produtiva em meios inteiramente apoiados em precisos grupos senhoriais e feudais, totalmente alheios às grandes cortes régias de então. Duas gerações de trovadores e de jograis, a primeira das quais remontando ao séc. xII, dezenas de nomes e centenas de textos produzidos em geografias muito diversas dão corpo a essa fase fundadora do trovadorismo galego-português, sem a existência da qual o tão glosado "período alfonsino" dificilmente teria adquirido a importância e a visibilidade que ainda hoje possui. 